\title{
Soft Tissue Filler Injections along the Nose: On-line Survey
}

\author{
Won Lee, MD, $\mathrm{PhD}^{1}$ \\ Seung Min Oh, MD, MBA ${ }^{2}$ \\ Wook $\mathrm{Oh}, \mathrm{MD}^{3}$ \\ Dae Geun Song, $\mathrm{MD}^{4}$ \\ Eun-Jung Yang, $\mathrm{MD}, \mathrm{PhD}^{5}$ \\ ${ }^{1}$ Yonsei E1 Plastic Surgery Clinic, Anyang, Korea \\ ${ }^{2}$ ON Clinic, Seoul, Korea \\ ${ }^{3}$ Samsung Feel Clinic, Seoul, Korea \\ ${ }^{4}$ Sanchaek Clinic, Seoul, Korea \\ ${ }^{5}$ Department of Plastic and Reconstructive \\ Surgery, Yonsei University College of Medicine, \\ Seoul, Korea
}

Received October 5, 2020

Accepted October 15, 2020

\footnotetext{
Correspondence

Won Lee

Yonsei E1 Plastic Surgery Clinic, Anyang

14072, Korea

E-mail: e1clinic@daum.net

https://orcid.org/0000-0001-7411-0198

(C) Korean Society for Laser, Dermatology and Trichology

(c) This is an open access article distributed under the terms of the Creative Commons Attribution NonCommercial License (http://creativecommons.org/ licenses/by-nc/4.0) which permits unrestricted noncommercial use, distribution, and reproduction in any medium, provided the original work is properly cited.
}

\section{Background and Objectives}

Although there are multiple guidelines on nasal dorsum augmentation with filler injections, complications are still common. Via a survey, we aimed to obtain an overview of current methods of augmentation rhinoplasty with filler injections and current problems associated therewith in order to suggest proper guidelines for administering injections along the nose.

\section{Materials and Methods}

The study analyzed voluntary responses to a questionnaire administered to Korean Medical Association Members who attended the Annual Congress of the Korean Association for Laser, Dermatology, and Trichology on May 19, 2019 in Seoul. The survey consisted of 11 questions concerning the use of filler injections in augmentation rhinoplasty and was conducted as an online survey accessed via the attendees smartphones during the conference.

\section{Resullts}

A total of 306 Korean doctors responded to the survey, describing their own methods for augmentation rhinoplasty with soft tissue filler injections. Among them, 162 tended to use only cannula injections; 107 doctors tended to use only needles. Also, 216 doctors stated that they administered injections at the supraperiosteal layer, with 70 injecting to subdermal layers concomitantly. Surprisingly, 57 doctors reported that they administered injections at the subcutaneous layer. Overall, 354 instances of complications with injections along the nose were reported, along with 54 cases of serious complications, such as skin necrosis and ocular complications.

\section{Conclusion}

Many doctors inject soft tissue filler at the supraperiosteal layer either by needle or cannula. They should be aware, however, that this technique is not $100 \%$ safe, despite guidelines suggesting that injecting at the supraperiosteal layer is relatively safe. To reduce vascular complication, subcutaneous injections should be avoided.

\section{Key words}

Hyaluronic acid, Filler, Blindness, Augmentation rhinoplasty, Vascular compromise 


\section{AESTHETICS}

\section{INTRODUCTION}

Soft tissue filler injections for nasal augmentation are common in Asian countries where desires for a more pronounced nasal dorsum are high [1]. Filler injections along the nose can be categorized according to the location along the nose where they are administered, including the radix, rhinion, supratip, and tip area. Compared to surgery, filler injections are relatively easy, although multiple precautions must be considered. First, vascular anatomy and variations therein should be well understood by physicians because of the possibility for serious vascular complications [2]. The intercanthal vein and dorsal nasal artery are of particular concern, as filler embolism in these vessels can elicit skin necrosis and ocular complications. The dorsal nasal artery tends to run along the superficial fatty layer of the nose at the radix and rhinion area. Accordingly, it is widely recommended that filler injections at the nose should be performed at the supraperiosteal layer, a deeper fatty layer. Second, physicians should be aware of soft tissue filler properties and their effect on the longevity of the filler and on the possible appearance that can be achieved [3]. Third, as a gentle injection is important, the size of the needle or cannula, which can affect the injection force, should be chosen carefully [4]. Although many reports have proposed guidelines for nasal dorsum augmentation with filler injections, complications continue to be reported [5]. In this study, we aimed to review current methods for filler injections for nasal dorsum augmentation among clinicians in Korea via an on-line survey and to highlight related complications associated therewith. This is the largest survey of nasal dorsum augmentation using filler injections to date.

\section{MATERIALS AND METHODS}

\section{Survey}

The study analyzed voluntary responses to an on-line survey conducted for members of the Korean Medical Associations who attended the Annual Congress of the Korean Association for Laser, Dermatology, and Trichology on May 19, 2019 in Seoul, Korea. The questionnaire was distributed to each doctor via their smartphones. The website address (http://vod.madeinreal.com:8080/vote/user/index. php?uid=VNHOKTM5CX) was sent to doctors who volunteered to participate in the survey via their phone number given at the time of registration at the conference. To begin the survey, participants were asked for their informed consent for use for their legal and personal data. After providing informed consent, participants were asked their age and 11 questions concerning actual filler techniques.
All responses were given directly through the electronical device. Responses to the survey were collected up until the closing of the conference at $6 \mathrm{pm}$, after which data were immediately analyzed. Approval of the study was obtained from the Institutional Review Board of Hanyang University Seoul Hospital.

\section{Statistical analysis}

Data on demographic and specialty factors are summarized as frequencies and percentages. The chi-square test was applied to analyze relationships between physician technique and demographic data. Fisher's exact test was used when the frequency of each cell was less than 5 . Odds ratios and their 95 percent confidence intervals were calculated using multivariate logistic regression to further examine any observed associations. All analyses were performed using SAS software (version 9.4 SAS Institute Inc., Cary, NC, USA). p-values less than 0.05 were considered statistically significant.

\section{RESULTS}

A total of 306 doctors (mean age, 42.72 years; range, 2769 years) agreed to voluntarily participate in the survey, and all of them completed it in its entirety. Respondent demographics and other characteristics are listed in Table 1.

Regarding filler practice, 164 of the 306 physicians responded that they only used cannulas to administer filler injections; 80 only used needles; and the remaining 48 responded that they used both. Regarding needle size, 19 doctors used needles smaller than 31 G: 41 used 30 G needles, 72 used 27-29 G needles, 25 used 25-26 G needles, 12 used 23-24 G needles, and three used needles larger than $22 \mathrm{G}$. When using cannulas, 44 physicians chose one smaller than 25 G, 29 used 24 G cannulas, 98 used 23 G cannulas, five used $22 \mathrm{G}$ cannulas, 26 used $21 \mathrm{G}$ cannulas, and three used cannulas larger than $20 \mathrm{G}$. Most physicians preferred an infralobular approach using a cannula, and 164 doctors who primarily used cannulas relied on a linear threading technique. The second most common technique for filler injection was perpendicular bolus injections using a needle ( $\mathrm{n}=$ 78). Additionally, 26 doctors responded that they injected from the glabella area, and two physicians used the nasal lateral area. 24 doctors used needles and cannulas concomitantly (Fig. 1). Injecting filler into the nose, 142 doctors positioned the needle or cannula at the supraperiosteal layer; 23 physicians administered injections at subdermal layers for anatomical layering; and 73 responded that they used both supraperiosteal layer and subdermal layer. Surprisingly, 57 doctors answered that they administered injections at 
Table 1. Baseline characteristics of the survey participants $(n=306)$

\begin{tabular}{|c|c|}
\hline Variables & Mean \pm SD/n (\%) \\
\hline Age & $42.72 \pm 8.18$ \\
\hline \multicolumn{2}{|l|}{ Sex } \\
\hline Male & $242(79.08)$ \\
\hline Female & $64(20.92)$ \\
\hline \multicolumn{2}{|l|}{ Number of filler injections (in a week) } \\
\hline $1-5$ & $198(64.71)$ \\
\hline $5-10$ & $54(17.65)$ \\
\hline $10-20$ & $35(11.44)$ \\
\hline$\geq 20$ & $19(6.21)$ \\
\hline \multicolumn{2}{|l|}{ Experience (years) } \\
\hline$<1$ & $101(33.01)$ \\
\hline $1-3$ & $51(16.67)$ \\
\hline $3-5$ & $33(10.78)$ \\
\hline $5-10$ & $62(20.26)$ \\
\hline$\geq 10$ & $59(19.28)$ \\
\hline \multicolumn{2}{|l|}{ Method } \\
\hline Cannula infralobular puncture & $164(53.59)$ \\
\hline Needle perpendicular to dorsum of nose skin & $78(25.49)$ \\
\hline Needle or cannula from glabellar area & $26(8.50)$ \\
\hline Needle from lateral side of nose & $2(0.65)$ \\
\hline $\begin{array}{l}\text { Cannula infralobular approach and needle } \\
\text { concomitantly }\end{array}$ & $24(7.84)$ \\
\hline Other & $12(3.92)$ \\
\hline \multicolumn{2}{|l|}{ Cannula size $(\mathrm{G})$} \\
\hline Smaller than 25 & 46 (15.03) \\
\hline 24 & $29(9.48)$ \\
\hline 23 & $98(32.03)$ \\
\hline 22 & $5(1.63)$ \\
\hline 21 & $25(8.17)$ \\
\hline Larger than 20 & $3(0.98)$ \\
\hline None & $100(32.68)$ \\
\hline \multicolumn{2}{|l|}{ Needle size (G) } \\
\hline Smaller than 31 & $19(6.21)$ \\
\hline 30 & $41(13.40)$ \\
\hline $27-29$ & $72(23.53)$ \\
\hline $25-26$ & $25(8.17)$ \\
\hline $23-24$ & $12(3.92)$ \\
\hline Larger than 22 & $3(0.98)$ \\
\hline None & $134(43.79)$ \\
\hline \multicolumn{2}{|l|}{ Target layer } \\
\hline Subdermal & $23(7.52)$ \\
\hline Subcutaneous & $57(18.63)$ \\
\hline Supraperiosteal (bone touch) & $142(46.41)$ \\
\hline Subdermal + supraperiosteal & $73(23.86)$ \\
\hline Other & $11(3.59)$ \\
\hline
\end{tabular}

Table 1. Continued

\begin{tabular}{lc}
\hline \multicolumn{1}{c}{ Variables } & Mean \pm SD/n (\%) \\
\hline Amount of filler (average) $(\mathrm{mL})$ & $46(15.03)$ \\
$0.1-0.2$ & $89(29.08)$ \\
$0.3-0.4$ & $49(16.01)$ \\
0.5 & $77(25.16)$ \\
$0.7-0.8$ & $43(14.05)$ \\
1.0 & $2(0.65)$ \\
$\geq 1.5$ & \\
Complications ( $=406)$ & $169(41.63)$ \\
Wider nasal dorsum area & $43(10.59)$ \\
Skin necrosis & $9(2.22)$ \\
Ocular complications & $49(12.07)$ \\
Granuloma or delayed hypersensitivity & $40(9.85)$ \\
Tyndall effect and/or transparent & $29(7.14)$ \\
Other & $67(16.50)$ \\
No complications & \\
\hline
\end{tabular}

Mean \pm standard deviation is presented for continuous variable and $\mathrm{n}(\%)$ is presented for categorical variables.

the subcutaneous layer (Fig. 2). The most commonly used filler was HA filler, and various reasons for choosing a filler product were given. Also, 304 doctors responded that they use less than $1 \mathrm{~mL}$ of filler during injection procedures, and 204 indicated that they perform secondary injections.

Only 67 doctors reported that they had not encountered complications associated with their preferred method of administering filler injections for nasal augmentation in their practice. 238 doctors reported 354 cases of complications. Of these, 169 cases involved complaints of a widened nose. There were 45 cases of skin necrosis, and nine cases of ocular complications (Fig. 3). Among the reported complications, a widened nose was correlated with filler injections at the supraperiosteal layer (Table 2).

\section{DISCUSSION}

Filler injection procedures along the nose differ between Asian and Western patients. In Asian patients, filler injections for nasal dorsum augmentation require relatively large amounts of product and a relative hard filler. In this survey, 238 (71\%) physicians reported that they primarily targeted the supraperiosteal layer for injections. Among them, 171 reported encountering a wider appearance after starting the filler. This is likely affected by the properties of the filler and the injection layer, although we were not able to investigate all of the filler products used. Also, we noted that doctors who preferred administering injections at the supraperiosteal layer encountered significantly more 


\section{AESTHETICS}

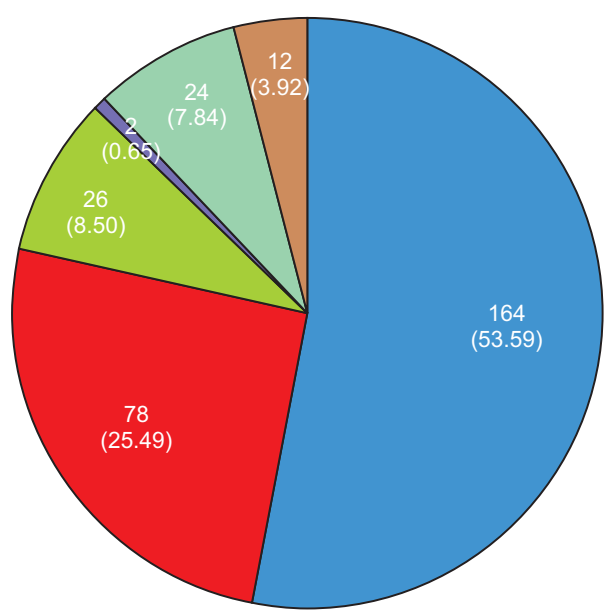

Cannula infralobular puncture

Needle perpendicular to dorsum of nose skin

$\square$ Needle or cannula from glabella area

$\square$ Needle from lateral side of nose

$\square$ Cannula infralobular approach and needle concomitantly

$\square$ Other

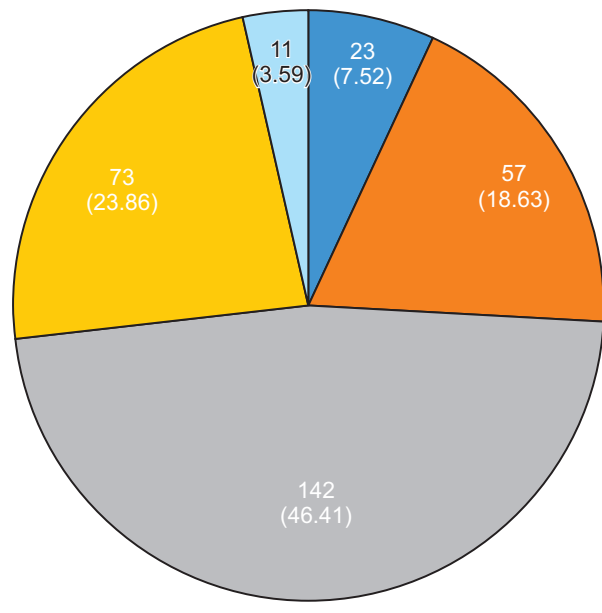

Subdermal

\section{Subcutaneous}

Supraperiosteal (bone touch)

Subdermal + supraperiosteal

Other

Fig. 1. Filler injection techniques.

Fig. 2. Targeted layers for filler injections.

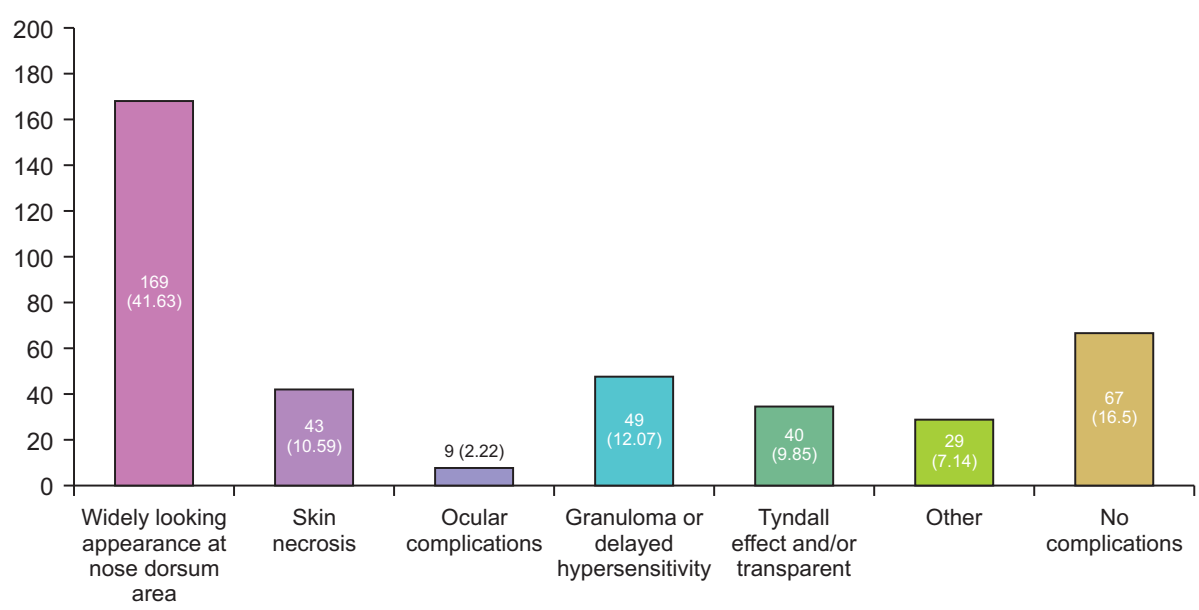

Fig. 3. Reported complications for aug mentation rhinoplasty by filler injection.

instances of a wider appearance for the nose. When administering filler injection at the supraperiosteal layer, a harder filler product is required to maintain the height of the nasal dorsum and to prevent migration of the filler. Lastly, the frequency of skin necrosis was about $15 \%$ (reported by 45 doctors who participated in the survey). That is higher than we expected.

Several reasons may account for the high incidence of skin necrosis reported in this survey. First is the layer in which filler is injected. Tansatit et al. [2] recommended administering injections at the supraperiosteal layer because it is a relatively safe plane. Our survey revealed that 216 of 
Table 2. Factors associated with the appearance of a wider nasal dorsum area

\begin{tabular}{|c|c|c|c|c|c|}
\hline Variables & $\mathrm{N}$ & Event & Odds ratio & 95\% C.I. & $\mathrm{p}$-value \\
\hline Age & 302 & 167 & 0.993 & $0.966-1.021$ & 0.635 \\
\hline Sex & 306 & 169 & & & 0.703 \\
\hline Male & 242 & 135 & Ref. & & \\
\hline Female & 64 & 34 & 0.898 & $0.517-1.561$ & 0.703 \\
\hline Number of filler injections (per week) & 306 & 169 & & & 0.612 \\
\hline $1-5$ & 198 & 106 & Ref. & & \\
\hline $5-10$ & 54 & 30 & 1.085 & $0.592-1.987$ & 0.792 \\
\hline $10-20$ & 35 & 23 & 1.663 & $0.784-3.528$ & 0.185 \\
\hline$\geq 20$ & 19 & 10 & 0.964 & $0.376-2.476$ & 0.940 \\
\hline Experience & 306 & 169 & & & 0.023 \\
\hline$<1$ & 101 & 43 & Ref. & & \\
\hline $1-3$ & 51 & 33 & 2.473 & $1.232-4.963$ & 0.011 \\
\hline $3-5$ & 33 & 21 & 2.360 & $1.048-5.314$ & 0.038 \\
\hline $5-10$ & 62 & 40 & 2.452 & $1.277-4.711$ & 0.007 \\
\hline$\geq 10$ & 59 & 32 & 1.599 & 0.838-3.051 & 0.155 \\
\hline Method & 292 & 164 & & & 0.001 \\
\hline Cannula infralobular puncture & 164 & 99 & Ref. & & \\
\hline Needle perpendicular to dorsum of nose skin & 78 & 37 & 0.593 & $0.344-1.020$ & 0.059 \\
\hline Needle or cannula from glabellar area & 26 & 8 & 0.292 & $0.120-0.710$ & 0.007 \\
\hline Cannula infralobular approach and needle concomitantly & 24 & 20 & 3.282 & $1.073-10.041$ & 0.037 \\
\hline Cannula size & 206 & 126 & & & 0.392 \\
\hline Smaller than 25 & 46 & 31 & Ref. & & \\
\hline 24 & 29 & 13 & 0.393 & $0.151-1.024$ & 0.056 \\
\hline 23 & 98 & 59 & 0.732 & $0.350-1.530$ & 0.407 \\
\hline 22 & 5 & 5 & > 999.999 & $<0.001->999.999$ & 0.981 \\
\hline 21 & 25 & 17 & 1.028 & $0.363-2.915$ & 0.958 \\
\hline Larger than 20 & 3 & 1 & 0.242 & $0.020-2.884$ & 0.262 \\
\hline Needle size & 172 & 93 & & & 0.285 \\
\hline Smaller than 31 & 19 & 14 & Ref. & & \\
\hline 30 & 41 & 18 & 0.280 & $0.085-0.921$ & 0.036 \\
\hline $27-29$ & 72 & 42 & 0.500 & $0.163-1.538$ & 0.227 \\
\hline $25-26$ & 25 & 13 & 0.387 & $0.107-1.402$ & 0.148 \\
\hline 23-24 & 12 & 5 & 0.255 & $0.055-1.185$ & 0.081 \\
\hline Larger than 22 & 3 & 1 & 0.179 & $0.013-2.425$ & 0.196 \\
\hline Target layer & 295 & 167 & & & 0.027 \\
\hline Subcutaneous & 57 & 22 & Ref. & & \\
\hline Subdermal & 23 & 14 & 2.475 & 0.917-6.679 & 0.074 \\
\hline Supraperiosteal & 142 & 88 & 2.593 & $1.378-4.877$ & 0.003 \\
\hline Subdermal + supraperiosteal & 73 & 43 & 2.280 & $1.123-4.630$ & 0.023 \\
\hline
\end{tabular}

306 doctors (71\%) followed this recommendation and administered injections at the supraperiosteal layer. However, 57 doctors (19\%) still injected filler at the subcutaneous layer (19\%), which is surprising in light of several studies recommending injection of the supraperiosteal layer for nasal dorsum augmentation [1,2,4-6]. We suspect that the majority of these instances would be due to a greater preference for the use of cannulas over needles and a belief that cannulas are safer.

Second is anatomical variation of the dorsal nasal ar- 


\section{AESTHETICS}

tery, which is directly related to the safety of nasal dorsum filler injection. Choi et al. [6] indicated that the dorsal nasal artery can cross the midline, and thus, care must be taken when injecting filler with a vertical bolus technique using a needle, as the dorsal nasal artery can be distributed across the nasal dorsum. Injections along the rhinion may be particularly dangerous because this is where the artery appears. Meanwhile, in studies using ultrasound, researchers reported that the dorsal nasal artery can be distributed in both the subcutaneous and supraperiosteal layers [7]. When performing filler injections with a cannula via an infralobular approach, the tip of the cannula can confront the dorsal nasal artery in patients with anatomical variations where the artery crosses the midline or runs through the supraperiosteal layer [8]. Therefore, when planning an injection procedure, practitioners should be aware of variations in vascularity and keep in mind that there are no completely safe procedures.

The third notable factor that can affect skin necrosis is the diameter of the needle or cannula. Among the 206 doctors who used cannulas, 46 (22\%) answered that they used one with a diameter smaller than $25 \mathrm{G}$. Because blood vessels can be punctured, the outer diameter of a needle or cannula used in an injection procedure is important, and a cannula smaller than $27 \mathrm{G}$ poses similar concerns as those for needles in filler practice [9]. The dorsal nasal artery is approximately 1-1.2 mm in diameter [6], and a $19 \mathrm{G}$ needle or cannula has an outer diameter of approximately $1 \mathrm{~mm}$, such that a needle or cannula smaller than this can readily perforate the artery. Physicians who use cannulas or needles less than $21 \mathrm{G}$ should always keep in mind that they can puncture the dorsal nasal artery and create vascular embolism.

\section{CONCLUSION}

Physicians should be aware that injections of soft tissue filler at the supraperiosteal layer of the nasal dorsum, either by a needle or cannula, are not completely safe. In filler procedure along the nasal dorsum, where a hard filler may be more effective. To reduce vascular complications, subcutaneous injections should be avoided.

\section{FINANCIAL SUPPORT}

None.

\section{CONFLICT OF INTEREST}

No potential conflict of interest relevant to this article was reported.

\section{REFERENCES}

1. Moon HJ. Injection rhinoplasty using filler. Facial Plast Surg Clin North Am 2018;26:323-30.

2. Tansatit T, Moon HJ, Rungsawang C, Jitaree B, Uruwan $S$, Apinuntrum $P$, et al. Safe planes for injection rhinoplasty: a histological analysis of midline longitudinal sections of the Asian nose. Aesthetic Plast Surg 2016;40:236-44.

3. Lee W, Hwang SG, Oh W, Kim CY, Lee JL, Yang EJ. Practical guidelines for hyaluronic acid soft-tissue filler use in facial rejuvenation. Dermatol Surg 2020;46:41-9.

4. Koh IS, Lee W. Hyaluronic acid filler and hyaluronidase. In: Koh IS, Lee W, editors. Filler Complications. Singapore: Springer; 2019. p.27-40.

5. Scheuer JF 3rd, Sieber DA, Pezeshk RA, Gassman AA, Campbell CF, Rohrich RJ. Facial danger zones: techniques to maximize safety during soft-tissue filler injections. Plast Reconstr Surg 2017;139:1103-8

6. Choi DY, Bae JH, Youn KH, Kim W, Suwanchinda A, Tanvaa T, et al. Topography of the dorsal nasal artery and its clinica implications for augmentation of the dorsum of the nose. $J$ Cosmet Dermatol 2018;17:637-42.

7. Lee W, Kim JS, Oh W, Koh IS, Yang EJ. Nasal dorsum augmentation using soft tissue filler injection. J Cosmet Dermatol. Forthcoming 2019. https://doi.org/10.1111/jocd.13018

8. Moon HJ, Lee W, Kim HD, Lee IH, Kim SW. Doppler ultrasonographic anatomy of the midline nasal dorsum. Aesthetic Plast Surg. Forthcoming 2020. https://doi.org/10.1007/ s00266-020-02025-1

9. Tansatit T, Apinuntrum P, Phetudom T. A dark side of the cannula injections: how arterial wall perforations and emboli occur. Aesthetic Plast Surg 2017;41:221-7. 